\title{
KEJADIAN MYALGIA PADA LANSIA PASIEN RAWAT JALAN
}

\author{
MYALGIA DISEASE ON ELDERLY IN OUTPATIENTS
}

\author{
Sumardiyono $^{1 *}$, Novy Wahyunengsi Lowa ${ }^{1}$, Abdullah Muchammad Azzam ${ }^{1}$, \\ Khairunnisa Nurul Huda ${ }^{1}$, Nadia Nurfauziah ${ }^{1}$ \\ ${ }^{1}$ Bagian Ilmu Kesehatan Masyarakat dan Kedokteran Pencegahan, \\ Fakultas Kedokteran Universitas Sebelas Maret \\ Jl. Ir. Sutami 36 A Surakarta \\ *E-mail: sumardiyono_uns@yahoo.com
}

\begin{abstract}
Histori Artikel:
ABSTRAK

Pendahuluan: Myalgia atau nyeri otot termasuk salah satu keluhan sakit yang cukup sering diderita manusia. Lansia juga sering mengeluhkan

Submitted:

$03 / 04 / 2017$ adanya myalgia. Proses menua mengakibatkan terjadinya penurunan fungsi dari organ-organ pada lansia, diantaranya penurunan fungsi muskuloskeletal, dan penurunan massa otot yang dapat menyebabkan gangguan pada otot. Tujuan penelitian ini adalah untuk mengetahui adanya hubungan kejadian myalgia pada lansia pasien rawat jalan.

Revised:

$21 / 04 / 2017$

Metode Penelitian: Penelitian ini merupakan penelitian observasional analitik dengan desain penelitian cross sectional. Penelitian dilakukan di Puskesmas Matesih Kabupaten Karanganyar dengan sampel para pasien rawat jalan tanggal 1-31 Mei 2016. Sampel dipilih secara simple random sampling sebanyak 97 sampel. Data sekunder berupa umur diambil dari

Accepted:

$17 / 06 / 2017$ rekam medik pasien. Data dianalisis secara statistik menggunakan uji Chi Square.

Hasil dan Pembahasan: Kejadian myalgia pada pasien rawat jalan lansia $(48,6 \%)$ lebih sedikit dibandingkan pasien rawat jalan bukan lansia $(51,4 \%)$.

Kesimpulan: Tidak terdapat hubungan signifikan antara kejadian myalgia dengan lansia pada pasien rawat jalan di Puskesmas Matesih Karanganyar $(\mathrm{p}>0,05)$.
\end{abstract}

Kata kunci: Myalgia, Lansia

\begin{abstract}
Introduction: Myalgia or fatigue is one of the most common disease affects humans. Elderly are also often complain of myalgia. Aging process resulted in a decreasing organ function, including musculoskeletal function, and muscle mass, which may cause abnormality to the muscle. This research aims to know the relationship between myalgia disease with elderly in outpatients.

Methods: This research was an observational analytic research with cross sectinal approach. This research was done at the health center Matesih Karanganyar with a sample of outpatients in May 30June 1, 2016. The sample was selected by simple random sampling as many as 97 samples. Secondary data are taken from the patient's medical record. Data was analyzed by Chi Square Test.

Results and Discussion: The incidence of myalgia at the health center Matesih Karanganyar in elderly outpatient (48.6\%) less than the younger outpatient (51.4\%).

Conclusion: There was no significant relationship between the incidence of myalgia with the elderly in outpatients at Matesih health centre in Karanganyar district ( $p>0.05$ ).
\end{abstract}

Keywords: Myalgia, Elderly 


\section{PENDAHULUAN}

Di Surakarta, myalgia merupakan salah satu masalah kesehatan yang penting. Berdasarkan data yang berasal dari masyarakat (community based data), angka kesakitan penduduk yang dikumpulkan oleh Puskesmas melalui sistem pencatatan dan pelaporan data, myalgia menduduki urutan ke $4(7,34 \%)$ dari 10 besar penyakit sesudah influenza (11,64\%), hipertensi esensial/primer $(9,59)$, dan nasopharingitis akut $(8,15 \%)$ pada pasien rawat jalan di Puskesmas Surakarta tahun 2014 (Depkes RI, 2014).

Myalgia dapat dikatakan sebagai sakit pada otot, berat, kaku atau rasa kram atau nyeri otot dan dapat terjadi kram di kaki di malam hari. Kelemahan otot juga dapat terjadi tanpa rasa ketidaknyamanan dan dapat dilihat pada penderita ketika tidak mampu membuka tutup botol, kesulitan menjentikkan jari atau kesulitan berdiri dari duduk di kursi (Tomaszewski, 2011). Muttaqin (2008), menyatakan bahwa myalgia atau nyeri otot termasuk salah satu keluhan yang cukup sering diderita manusia. Myalgia atau disebut juga nyeri otot merupakan gejala dari banyak penyakit dan gangguan pada tubuh. Penyebab umum myalgia adalah penggunaan otot yang salah atau otot yang terlalu tegang. Pemakaian otot yang berlebihan dapat mengakibatkan otot-otot yang digunakan mengalami kekurangan oksigen, sehingga terjadi suatu proses oksidasi anaerob yang akan menghasilkan asam laktat. Asam laktat inilah yang akan menimbulkan rasa pegal atau nyeri. Myalgia dapat dialami dalam waktu singkat, misalnya otot kram, atau berlanjut sampai beberapa hari, bahkan beberapa bulan atau menahun dapat mengganggu penderita karena intensitas yang berfluktuasi. Penyakit ini tidak mengancam aktivitas hidup penderita, namun bila timbul terus- menerus dapat menyebabkan penderita menjadi frustasi karena bisa saja menjadi hambatan dalam hal bekerja maupun aktivitas harian lainnya yang ada akhirnya dapat menurunkan kualitas hidup penderita. Sebagian penderita myalgia terkadang mengkonsumsi obat penghilang rasa nyeri untuk waktu yang lama. Hal ini berisiko efek samping obat jika dikonsumsi berlebihan atau tidak menurut anjuran dokter, misalnya dapat menyebabkan hambatan pembentukan sel darah merah, terjadi sakit maag (gartritis), ataupun keropos tulang.
Lansia merupakan tahap akhir siklus kehidupan. Lansia juga merupakan tahap perkembangan normal yang akan dialami oleh setiap individu yang mencapai usia lanjut dan merupakan kenyataan yang tidak dapat dihindari. Lansia adalah kelompok orang yang sedang mengalami suatu proses perubahan yang bertahap dalam jangka waktu beberapa dekade. Pada tahap ini individu mengalami banyak perubahan baik secara fisik maupun mental, khususnya kemunduran dalam berbagai fungsi dan kemampuan yang pernah dimilikinya (Soejono, 2000). Menurut WHO tahun 2012, Populasi lansia di kawasan Asia Tenggara mencapai 8\% atau sekitar 142 juta jiwa. Pada tahun 2011 jumlah penduduk lansia di Indonesia sekitar 18,27 juta orang atau 7,58 persen dari total penduduk (BPS, 2012).

Proses menua mengakibatkan terjadinya penurunan fungsi dari organ-organ lansia, diantaranya penurunan penglihatan, kemunduran sel saraf, penurunan fungsi muskuloskeletal, dan penurunan massa otot yang dapat menyebabkan gangguan pada otot, salah satunya adalah myalgia atau nyeri otot (Darmojo, 2009). Myalgia dapat mengakibatkan kekakuan pada otot jika tidak dilakukan perawatan sesegera mungkin. Untuk itu sangat diperlukan upaya promotif, preventif, kuratif dan rehabilitatif yang memperhatikan aspek fisik, psikis, sosial dan lingkungan (Mubarak, 2010).

Myalgia merupakan rasa sakit atau kelelahan otot yang sering dikeluhkan pasien di Puskesmas Matesih, Puskesmas lain maupun di Rumah Sakit yang biasanya bersifat akut dan sering menyerang secara spontan serta bisa disebabkan aktivitas fisik yang berlebihan, pengaruh obat ataupun pengobatan lain. Di wilayah kerja Puskesmas Matesih, myalgia merupakan penyakit yang sering dirasakan oleh para lansia di masyarakat. Penyebab yang paling sering disebabkan oleh ketegangan (kontraksi) yang berlebihan, saat latihan atau bekerja berat. Oleh karena itu, peneliti ingin menganalisis kejadian myalgia pada lansia pasien rawat jalan di Puskesmas Matesih Kabupaten Karanganyar.

\section{METODE PENELITIAN}

Penelitian ini merupakan penelitian observasional analitik dengan desain penelitian cross sectional. Penelitian ini dilakukan di Puskesmas Matesih Kabupaten 
Karanganyar dengan sampel para pasien rawat jalan tanggal 1-31 Mei 2016. Pada tanggal 1-31 Mei 2016 terdapat 3257 pasien rawat jalan, kemudian dengan rumus Slovin didapatkan 97 sampel untuk mewakili populasi. Sampel dipilih secara simple random sampling.

Data sekunder berupa umur diambil dari rekam medik pasien. Menurut WHO lanjut usia (lansia) adalah kelompok penduduk yang berumur 60 tahun atau lebih.

Variabel bebas pada penelitian ini adalah usia dengan skala ukur nominal (kategorikal) dan variabel terikatnya adalah kejadian myalgia dengan skala ukur nominal (kategorikal). Data dianalisis secara statistik menggunakan uji Chi Square dengan tingkat kemaknaan $\alpha=0,05$.

\section{HASIL DAN PEMBAHASAN}

Penelitian mengenai hubungan kejadian myalgia dengan lansia pada pasien rawat jalan di Puskesmas Matesih Kabupaten Karanganyar pada tanggal 1-31 Mei 2016 didapatkan hasil penelitian seperti tersaji pada tabel 1.

Tabel 1. Karakteristik Sampel berdasar kejadian myalgia dan lansia

\begin{tabular}{llcc}
\hline \multirow{2}{*}{ Variabel } & \multicolumn{2}{c}{ Kategori } & \multicolumn{2}{c}{ Total $(\mathrm{n}=97)$} \\
\hline \multirow{2}{*}{ Kejadian myalgia } & Myalgia & 35 & 36,1 \\
\multirow{2}{*}{ Usia } & Bukan Myalgia & 62 & 63,9 \\
& Lansia & 38 & 39,2 \\
& Bukan lansia & 59 & 60,8 \\
\hline
\end{tabular}

Sumber: Data sekunder (2016)

Berdasarkan tabel 1 dapat dilihat jumlah pasien rawat jalan dengan diagnosis myalgia pada penelitian ini adalah 35 orang $(36,1 \%)$ dan jumlah pasien rawat jalan dengan diagnosis bukan myalgia adalah 62 orang
(63,9\%). Pasien rawat jalan yang berusia lansia $(39,2 \%)$ lebih sedikit dibandingkan pasien rawat jalan yang bukan berusia lansia $(60,8 \%)$.

Tabel 2. Hasil Analisis Bivariat Kejadian Myalgia pada Lansia

\begin{tabular}{|c|c|c|c|c|}
\hline \multirow[b]{2}{*}{ Variabel } & \multicolumn{2}{|c|}{ Lansia } & \multirow[b]{2}{*}{$\begin{array}{c}\text { Total } \\
(\%)\end{array}$} & \multirow[b]{2}{*}{$\mathrm{p}$} \\
\hline & $\begin{array}{c}\text { Ya } \\
\text { n (\%) }\end{array}$ & $\begin{array}{l}\text { Tidak } \\
\text { n (\%) }\end{array}$ & & \\
\hline Myalgia & $\begin{array}{c}17 \\
(48,6)\end{array}$ & $\begin{array}{c}18 \\
(51,4)\end{array}$ & $\begin{array}{c}35 \\
(100)\end{array}$ & 0,154 \\
\hline Buka myalgia & $\begin{array}{c}21 \\
(33,9)\end{array}$ & $\begin{array}{c}41 \\
66,1\end{array}$ & $\begin{array}{c}62 \\
100\end{array}$ & \\
\hline
\end{tabular}

Sumber: Data sekunder (2016)

Berdasarkan tabel 2 dapat diketahui bahwa kejadian myalgia pada pasien rawat jalan lansia (48,6\%) lebih sedikit daripada pasien rawat jalan bukan lansia $(51,4 \%)$. Tabel 2 juga menunjukkan dari 38 orang pasien rawat jalan lansia, 17 orang diantaranya mengalami myalgia dan 21 orang lainnya tidak mengalami myalgia, sedangkan dari 59 pasien rawat jalan bukan lansia, 18 orang orang diantaranya mengalami myalgia dan 41 orang lainnya tidak mengalami myalgia. Tabel 2 juga menunjukkan tidak adanya hubungan signifikan antara kejadian myalgia dengan lansia ( $p>0,05)$.

Hasil penelitian ini sejalan dengan penelitian yang telah dilakukan sebelumnya oleh Raad et al. (2004), yang menyatakan tidak ada hubungan antara umur dengan kejadian myalgia $(\mathrm{p}=0,73)$. Pada penelitian ini juga diinformasikan bahwa jenis kelamin tidak berhubungan secara signifikan terhadap kejadian myalgia $(p=0,27)$. Namun penelitian ini berbeda dengan penelitian di Pakistan yang dilakukan oleh Zubair et al. (2015) pada kejadian myalgia di Rumah Sakit, dimana hasil penelitiannya menunjukkan bahwa variabel usia berpengaruh terhadap kejadian myalgia $(\mathrm{p}=0,01)$, sedangkan variabel lain tidak berpengaruh yang bermakna terhadap kejadian myalgia, seperti jenis kelamin $(p=0,67)$, diabetes melitus $(\mathrm{p}=0,63)$, hipertensi $(\mathrm{p}=0,83)$, dan penyakit jantung koroner $(\mathrm{p}=0,86)$.

Hasil penelitian ini juga berbeda dengan penelitian sebelumnya yang menyatakan prevalensi nyeri pada lansia mengalami peningkatan $65-80 \%$ dan sebagian besar 
diantaranya memerlukan perawatan di rumah sakit karena menderita nyeri. kondisi tersebut tidak mengejutkan karena pada populasi lansia terdapat peningkatan risiko terjadinya nyeri yang sering sulit diobati, seperti yang disebabkan oleh penyakit artritis, neuropati diabet, nyeri pasca herpetik, neuropati pascastrok, parkinson dan penyakit terminal (King, 2000; Cardenas, 2000).

Nyeri merupakan pengalaman subyektif yang dapat mempengaruhi kualitas hidup lansia termasuk gangguan kemampuan fisiknya. Permasalahan nyeri pada lansia adalah kesulitan menegakkan diagnosis dan menentukan terapi, sehingga memperberat penyakit yang mendasari. Penatalaksanaan medis kasus nyeri pada lansia seringkali terjadi kegagalan. Penyebab utama kegagalan tersebut adalah adanya beberapa keyakinan yang tidak tepat, yaitu 1) nyeri pada lansia adalah sesuatu yang normal dan tidak perlu penanganan medis professional; 2) penderita nyeri lansia lebih baik dalam mengatasi nyeri dibandingkan usia muda sehingga tidak perlu penanganan khusus; dan 3) nyeri kronis mungkin dapat menyebabkan penderita lansia tidak nyaman tetapi tidak berbahaya (Rahmawati, 2006).

Kelemahan studi ini adalah peneliti tidak melakukan pengambilan data secara langsung pada subjek. Seperti diketahui bahwa nyeri merupakan keluhan yang objektif yang dirasakan oleh setiap individu, maka untuk mendapatkan data yang lebih akurat diharapkan melakukan pemeriksaan secara langsung pada subjek, serta diperlukan metode yang objektif untuk menentukan rasa nyeri pada lansia, mengingat rasa nyeri ini dipengaruhi oleh banyak faktor. Selain itu, peneliti juga tidak melakukan pengujian analisis terhadap faktor-faktor risiko myalgia lainnya sehingga mungkin menimbulkan bias dalam hasil penelitian, karena kemungkinan myalgia bisa disebabkan oleh karena: 1) Gangguan tidur, yaitu pada orang yang menderita gangguan tidur terkadang merasakan nyeri otot akibat dari ansietas karena stres; 2) Ketidakseimbangan hormon, terjadi jika salah satu hormon reproduksi tidak berfungsi secara normal sehingga tubuh beralih menggunakan adrenalin yang seharusnya dipakai untuk mekanisme flight or fight pada saat keadaan darurat sehingga berdampak nyeri otot persisten atau disebut fibromyalgia kronis; 3) Defisiensi vitamin yang disebabkan oleh diet dan gaya hidup yang kurang sehat; 4) Penggunaan obatobatan, misalnya obat penurun kadar kolesterol memiliki efek samping nyeri otot; 5) Penyakit autoimun, seperti rheumatoid asthritis dan lupus yang merupakan kondisi dimana system imun menyerang jaringan/organ tubuh.

\section{KESIMPULAN}

Tidak terdapat hubungan signifikan antara kejadian myalgia dengan lansia pada pasien rawat jalan di Puskesmas Matesih Karanganyar.

\section{Ucapan terima Kasih}

Peneliti menyampaikan terima kasih kepada dr. Wahyu Purwadi Rahmat, M.Kes., selaku Kepala Puskesmas Matesih Karanganyar, yang telah memberikan ijin kepada peneliti untuk penelitian di Puskesmas Matesih Karanganyar.

\section{Daftar Pustaka}

Badan Pusat Statistik (BPS). (2012). Data Statistik Indonesia: Jumlah Penduduk menurut Kelompok Umur, Jenis Kelamin, Provinsi, dan Kabupaten/Kota. Available at: http://data.go.id/dataset/jumlahpenduduk-berdasarkan-jenis-kelamindan-kelompok-usia

Cardenas D.D, Egan KJ. (2000). Management of chronic psain. In: Kottke FJ, Lehmann JF. Krusen's Handbook of Physical medicine and rehabilitation. 4th ed. Philadelphia: WB Saunders Company; 2000. p. 1163-7.

Darmojo B. (2009). Buku ajar Geriatri (Ilmu Kesehatan Usia Lanjut). Jakarta: Balai Penerbit Fakultas Kedokteran Universitas Indonesia.

Darmojo R.B. (2004). Pola Penyakit dan Keluhan Pada Golongan Penyakit Pada Usia Lanjut Agar Tetap Sehat dan Berkualitas. Semarang: FK UNDIP, 2, 810.

Depkes RI (2014). Profil Kesehatan Kota Surakarta Tahun 2014. p:41. Available at:

www.depkes.go.id/resources/downloa d/3372_Jateng_Kota_Surakarta_2014.p $\mathrm{df}$

King S.A. (2000). Shattering the myths about geriatric pain. Geriatric Times; 2000; 1:5-6. 
Muttaqin A. (2008). Buku Ajar Asuhan keperawatan Kliendengan Gangguan Sistem Muskuloskeletal. Jakarta: EGC.

Mubarak (2010). Ilmu Keperawatan Komunitas. Jakarta: Salemba.

Rahmawati et al. (2006). Nyeri musculoskeletal dan hubungannya dengan kemampuan fungsional fisik pada lanjut usia. Jakarta: Bagian Anatomi Fakultas Kedokteran Universitas Trisakti.

Raad I., Hachem R., Hanna H. (2004). Relationship between myalgias/arthralgias occurring in patients receiving quinupristin/dalfopristin and biliary dysfunction. J Antimicrob Chemother 2004; 53 (6): 1105-1108. doi: $10.1093 / \mathrm{jac} / \mathrm{dkh} 234$
Setiawati A., Suyatna, dan Sulistia G.G. (2007). Farmakologi dan Terapi. Jakarta: Departemen Farmakologi dan Terapeutik FKUI.

Soejono. (2000). Pedoman Pengelolaan Kesehatan Pasien Geriatric untuk Dokter dan Perawat. Jakarta: FK UI, 60-76.

Tomaszewski M, Stepien KM, Tomaszewska J, et al. (2011). Statin-induced myopathies. Pharmacol Rep PR 2011; 63:859-66.

Zubair A.K., Ahmad I.N., Ahmad A. (2015). Association of vitamin D with statin induced myalgia. Pakistan Journal of Neurological Sciences (PJNS). Vol.10: Iss. 2, Article 6. Available at: http://ecommons.aku.edu/pjns/vol10 Liss $2 / 6$. 